\title{
Psychological factors: anxiety, depression, and somatization symptoms in low back pain patients
}

This article was published in the following Dove Press journal:

Journal of Pain Research

I February 2013

Number of times this article has been viewed

\author{
Abdulbari Bener ${ }^{1-3}$ \\ Mohamud Verjee 4 \\ Elnour E Dafeeah ${ }^{5}$ \\ Omar Falah ${ }^{4}$ \\ Taha Al-Juhaishi ${ }^{4}$ \\ Josia Schlogl ${ }^{4}$ \\ Alhasan Sedeeq ${ }^{4}$ \\ Shehryar Khan ${ }^{4}$
}

'Department of Medical Statistics and Epidemiology, Hamad Medical

Corporation, ${ }^{2}$ Department of Public

Health, Weill Cornell Medical

College, Doha, Qatar; ${ }^{3}$ Department of Evidence for Population Health Unit, School of Epidemiology and Health Sciences, The University of Manchester, Manchester, UK; ${ }^{4}$ Department of Medical Education, Weill Cornell Medical College, ${ }^{5}$ Department of Psychiatry, Hamad Medical Corporation, Doha, Qatar

Correspondence: Abdulbari Bener Department of Medical Statistics and Epidemiology, Hamad Medical Corporation, PO Box 3050, Doha, Qatar Tel +974 $44393765 ;+97444393766$ Fax +974 44393769

Email abener@hmc.org.qa; abb2007@qatar-med.cornell.edu
Aim: To determine the prevalence of low back pain (LBP), investigate the sociodemographic characteristics of patients with LBP, and examine its association with psychological distress such as anxiety, depression, and somatization.

Subjects and methods: Of the 2742 patients approached, 2180 agreed to participate in this cross-sectional study (79.5\% response rate). The survey was conducted among primary health care visitors from March to October 2012 and collected sociodemographic details and LBP characteristics. General Health Questionnaire-12 was used to identify the probable cases. Anxiety was assessed with Generalized Anxiety Disorder-7, depression was assessed with Patient Health Questionnaire-9, and somatization was measured with Patient Health Questionnaire-15.

Results: The study sample consisted of $52.9 \%$ males and $47.1 \%$ females. The prevalence of LBP was $59.2 \%$, comprising $46.1 \%$ men and $53.9 \%$ women. LBP was significantly higher in Qataris (57.9\%), women (53.9\%), housewives (40.1\%), and individuals with higher monthly income $(53.9 \%)$. Somatization $(14.9 \%)$ was observed more in LBP patients, followed by depression (13.7\%) and anxiety disorders $(9.5 \%)$. The most frequently reported symptoms were "headaches" (41.1\%) and "pain in your arms, legs, or joints" (38.5\%) in LBP patients with somatization. The most frequent symptoms among depressed LBP patients were "thinking of suicide or wanting to hurt yourself" (51.4\%) and "feeling down, depressed, or hopeless" (49.2\%). "Not being able to stop or control worrying" (40.2\%), "worrying too much about different things" (40.2\%), and "feeling afraid as if something awful might happen" (40.2\%) were the most common anxiety symptoms in LBP patients. Psychological distress such as anxiety $(9.5 \%$ versus $6.2 \%$ ), depression ( $13.7 \%$ versus $8.5 \%$ ), and somatization (14.9\% versus $8.3 \%)$ were significantly higher in LBP patients.

Conclusion: The prevalence of LBP in this study sample was comparable with other studies. Furthermore, psychological distress such as anxiety, depression, and somatization were more prevalent in LBP patients compared to patients without LBP.

Keywords: somatization, anxiety, depression, low back pain, primary health care

\section{Introduction}

Low back pain (LBP) is an increasing economic and health problem affecting nearly $80 \%$ of the general population. ${ }^{1}$ LBP, a leading cause of disability, has a significant economic impact not only on lost productivity, but also on health care expenditure. LBP is ranked first as a cause of disability and inability to work, and is expected to affect most adults at some point during their lifetime. ${ }^{2}$ It is a symptom commonly presented to general practitioners. It is an important clinical and public health problem, and is the most common illness among humans after the common cold. LBP is the most prevalent form of chronic musculoskeletal pain worldwide, often leading to 
disability. ${ }^{3}$ It has been established that LBP is the second most frequent cause of disability in the European adult population. Eight in every ten adults experience LBP at some point in their lifetime.

LBP is a complex condition produced by multiple factors. There is evidence that psychosocial difficulties and psychological factors might be associated with LBP. ${ }^{4}$ Despite the recognition that excessive pain complaints are associated with psychological problems, the exact relationship between pain behavior and psychological factors continues to be unclear. It was reported that LBP can have a substantial negative impact on quality of life and that psychological distress is common in patients with LBP. ${ }^{5}$ The hypothesis is that subjects exhibiting excessive pain complaints would be more depressed than those who do not exhibit excessive levels of pain complaints. Due to its medical, social, and financial importance, LBP is an important concern of the medical world. It was reported that the risk of LBP increases rapidly with greater amounts of physical work and psychological distress. ${ }^{4}$ Primary prevention studies are important to identify the risk factors predictive of LBP before additional interventions can be developed.

A previous study by Bener et al reported that depression and somatization were very common in LBP patients. ${ }^{5}$ Also, a recent study observed a high rate of comorbidity of somatization, depression, anxiety, and stress in the studied population and indicated a strong association between these psychological disorders in patients. ${ }^{6}$ Considering the results of these two studies, the authors understood the importance of focusing on LBP issues in the general population of Qatar and exploring the potential psychological differences between patients with and without LBP. Hence, the purpose of this study was to determine the prevalence of LBP and sociodemographic characteristics of LBP patients and examine its association with psychological distress such as anxiety, depression, and somatization.

\section{Subjects and methods}

This is a cross-sectional study and the study included subjects aged 15-65 years who attended primary health care centers throughout Qatar. Primary health care centers are frequented by all levels of the general population as a gateway to specialist care. The study was conducted among patients visiting twelve health centers - nine centers from urban areas and three centers from semi-urban areas as a representative sample of the community.

Data collection took place from March to October 2012. Qualified nurses were trained to interview the patients and complete the questionnaires. A representative sample of 2742 subjects aged 15-65 years was computed based on a reported prevalence of LBP in the United Arab Emirates (50\%-64\%) with a $2.5 \%$ error of estimation and $5 \%$ level of significance (type I error). ${ }^{7,8}$ Accordingly, 2742 subjects aged 15-65 years were approached and 2180 subjects agreed to take part in this study, thus giving a response rate of $79.5 \%$. Verbal consent was taken from every patient after explaining the objective of the study and its importance to the community. The study excluded patients aged $<15$ years and $>65$ years, patients with any cognitive or physical impairment, and patients who refused to give consent to take part in the study. Elderly individuals $>65$ years are at high risk for any kind of physical impairment.

The survey instrument was tested on 100 patients who visited the health centers and thus validated the questionnaire. The questions related to LBP in the questionnaire confirmed the number of patients with LBP in the studied population. For identifying the psychiatric disorders, the twelve-item General Health Questionnaire (GHQ-12) ${ }^{9}$ was used to identify the probable cases in the studied population. After identifying the probable cases for psychiatric disorders, the Patient Health Questionnaire nine-item depression module (PHQ-9), ${ }^{10}$ seven-item Generalized Anxiety Disorder Scale (GAD-7), ${ }^{11}$ and PHQ 15-item somatic symptom module (PHQ-15) ${ }^{12}$ were used to investigate the somatization, depression, and anxiety of the subjects, respectively. Each questionnaire is scored by summing the ratings for all questions. A score of $\geq 15$ on PHQ-15 and PHQ-9 indicates a severe somatization disorder and severe depression, respectively. A score of $\geq 11$ on GAD-7 indicates severe anxiety.

The first part of the questionnaire included the sociodemographic details of the patients and other factors involved with the LBP. The second part was the diagnostic screening questionnaire which consisted of questions about symptoms and signs of mental disorders such as anxiety disorder, depression, and somatization. Patients were asked to answer the questions by grading them from zero to three (zero for "not at all," one for "several days," two for "more than half the days," and three for "nearly every day") for depression and anxiety disorders. For somatic symptoms, questions were graded from zero to two (zero for "bothered not at all," one for "bothered a little," and two for "bothered a lot"). The data was collected through a validated selfadministered questionnaire with the help of qualified nurses. The nurses conducted a face-to-face interview with every patient and completed the questionnaires. The psychiatrists had screened the completed psychiatric questionnaires for their adequacy in confirming probable cases of LBP. 
For some participants who were illiterate, the nurses read out the questions to complete the questionnaires. Following completion of the questionnaires by the patient, the provisional diagnosis score was calculated from the responses, which then was confirmed by psychiatrists. Approval was obtained from the Hamad Medical Corporation Institutional Review Board for conducting this research in Qatar.

Assumptions of normal distribution and homogeneity of variance were checked for continuous scale variables such as depression, somatization, and anxiety scores by using histograms with normal distribution curves and Levene's test, respectively. Since the assumptions were fulfilled, Student's $t$-test was used to ascertain the significance of differences between mean values of two continuous variables and confirmed by the nonparametric Mann-Whitney $U$ test. Chi-squared analysis was performed to test for differences in proportions of categorical variables between two or more groups. In $2 \times 2$ tables, the Fisher's exact test (two-tailed) replaced the Chi-squared test if the assumptions underlying Chi-squared were violated, ie, in cases of small sample size and when the expected frequency was less than five in any of the cells. $P<0.05$ was considered as the cut-off value for significance.

\section{Results}

Table 1 reveals the sociodemographic characteristics of the subjects studied according to their LBP status. The prevalence of LBP was $59.2 \%$ in the studied population comprising $52.9 \%$ men and $47.1 \%$ women. The majority of subjects were 45-54 years old (36.9\%). LBP was significantly higher in Qataris $(57.9 \% ; P<0.001)$, women $(53.9 \% ; P<0.001)$, housewives $(40.1 \% ; P<0.001)$, and individuals with higher monthly income $(53.9 \% ; P=0.002)$. Smokers $(20.5 \%$; $P=0.003)$, overweight individuals $(45.4 \% ; P<0.001)$, and subjects using a sponge mattress for sleeping (47.8\%; $P=0.020$ ) had a significantly higher frequency of LBP.

Table 2 shows the mean scores of somatization, depression, and anxiety in subjects with and without LBP. The mean score of anxiety $(8.1 \pm 2.9$ versus $6.4 \pm 3.3 ; P<0.001)$, depression $(10.1 \pm 3.3$ versus $9.0 \pm 3.5 ; P=0.001)$, and somatization $(16.1 \pm 4.3$ versus $14.2 \pm 5.6 ; P<0.001)$ was significantly higher in patients with LBP compared to subjects without LBP.

Table 3 examines the symptom frequencies of anxiety, depression, and somatization among patients with LBP. The most frequently reported symptom was "headaches" (41.1\%), followed by "pain in your arms and legs or joints" (38.5\%). For LBP patients with depression, the most frequent symptoms were "thinking of suicide or wanting to hurt yourself" (51.4\%) and "feeling down, depressed, or hopeless" (49.2\%). "Not being able to stop or control worrying" (40.2\%), "worrying too much about different things" (40.2\%), and "feeling afraid as if something awful might happen" $(40.2 \%)$ were the most commonly rated anxiety symptoms. The least reported somatization symptom in LBP patients was "shortness of breath" (17.2\%), while "feeling tired or having little energy" (16.4\%) was the least reported depression symptom in depressed LBP patients. "Trouble relaxing" (20.5\%) was the least reported symptom in anxiety patients.

Figure 1 shows the distribution of psychiatric disorders in subjects with and without LBP. The prevalence of severe anxiety $(9.5 \%$ versus $6.2 \% ; P=0.007)$, depression $(13.7 \%$ versus $8.5 \% ; P=0.002)$, and somatization $(14.9 \%$ versus $8.3 \% ; P<0.001)$ was significantly higher in LBP patients compared to patients without LBP.

\section{Discussion}

LBP is widely regarded as a biopsychosocial problem. ${ }^{13}$ The physical and psychological stressors are known to increase LBP risk. This cross-sectional study found that psychosocial factors were associated with the episodes of LBP. The data revealed a significant association between the prevalence of psychological distress and LBP, which is in accordance with earlier observations. ${ }^{4,14}$ The prevalence of somatization (14.9\% versus $8.3 \% ; P<0.001)$, depression $(13.7 \%$ versus $8.5 \% ; P=0.002)$, and anxiety disorders $(9.5 \%$ versus $6.2 \%$; $P=0.007$ ) was higher in the study sample of LBP patients compared to their healthy counterparts. In contrast, Dickens et al showed that patients with and without excessive pain behavior had similar levels of anxiety and depression, especially in women. ${ }^{15}$

The prevalence of LBP in the study sample $(59.2 \%)$ is within the reported range $(50 \%-80 \%)$ of those in a modern industrial society who will experience LBP more than once in their lifetime. ${ }^{16}$ In another study by Manchikanti et al, lifetime prevalence of LBP was reported as $69 \%-80 \% .{ }^{17}$ The prevalence rate in the current study is close to the rate observed in neighboring countries such as the United Arab Emirates (64.7\%) and Saudi Arabia (51.6\%). ${ }^{8,18}$ It was reported in a recent study that the prevalence of LBP could be as high as $60 \%-80 \%$ in the US and European adult population. ${ }^{19}$ Although the current prevalence rate agrees with the studies conducted in the gulf region, it was higher than the prevalence observed in developed countries such as the UK (49\%) and Canada (47\%). ${ }^{20,21}$ 
Table I Sociodemographic characteristics of the study population according to low back pain (LBP)

\begin{tabular}{|c|c|c|c|c|}
\hline Variables & $\begin{array}{l}\text { Total } \\
n=2180\end{array}$ & $\begin{array}{l}\text { LBP } \\
n=1290\end{array}$ & $\begin{array}{l}\text { Without LBP } \\
n=890\end{array}$ & $P$-value \\
\hline \multicolumn{5}{|l|}{ Age groups (years) } \\
\hline$<35$ & $313(14.4)$ & $197(15.3)$ & $116(13.0)$ & 0.438 \\
\hline $35-44$ & $483(22.2)$ & $276(21.4)$ & $207(23.3)$ & \\
\hline $45-54$ & $805(36.9)$ & $477(37.0)$ & 328 (36.9) & \\
\hline$\geq 55$ & $579(26.6)$ & $340(26.0)$ & $239(26.9)$ & \\
\hline \multicolumn{5}{|l|}{ Nationality } \\
\hline Qatari & $1097(50.3)$ & 747 (57.9) & $350(39.3)$ & $<0.00$ I \\
\hline Non-Qatari & $1083(49.7)$ & $543(42.1)$ & $540(60.7)$ & \\
\hline \multicolumn{5}{|l|}{ Gender } \\
\hline Male & $1153(52.9)$ & $595(46.1)$ & $558(62.7)$ & $<0.001$ \\
\hline Female & $1027(47.1)$ & $695(53.9)$ & $332(37.3)$ & \\
\hline \multicolumn{5}{|l|}{ Body mass index } \\
\hline$<24.9$ & $670(30.7)$ & $336(26.0)$ & $334(37.5)$ & $<0.001$ \\
\hline $25-30$ & $1011(46.4)$ & $586(45.4)$ & $425(47.8)$ & \\
\hline$>30$ & 499 (22.9) & $368(28.5)$ & $|3|(\mid 4.7)$ & \\
\hline \multicolumn{5}{|l|}{ Marital status } \\
\hline Single & I 58 (7.2) & $87(6.7)$ & $71(8.0)$ & 0.275 \\
\hline Married & $2022(92.8)$ & $1203(93.3)$ & $819(92.0)$ & \\
\hline \multicolumn{5}{|l|}{ Education level } \\
\hline Illiterate & $350(16.1)$ & $211(16.4)$ & $139(\mid 5.6)$ & 0.331 \\
\hline Elementary & $417(19.1)$ & $254(19.7)$ & $163(18.3)$ & \\
\hline Intermediate & $462(2 \mid .2)$ & $256(19.8)$ & $206(23.1)$ & \\
\hline Secondary & $497(22.8)$ & $305(23.6)$ & $192(21.6)$ & \\
\hline University & $454(20.8)$ & $264(20.5)$ & $190(21.3)$ & \\
\hline \multicolumn{5}{|l|}{ Occupational status } \\
\hline Housewife & $692(31.7)$ & $517(40.1)$ & 175 (19.7) & $<0.00 \mathrm{I}$ \\
\hline Sedentary and professional & $385(17.7)$ & $200(15.5)$ & $185(20.8)$ & \\
\hline Clerk & $732(33.6)$ & $372(28.8)$ & $360(40.4)$ & \\
\hline Business & $212(9.7)$ & $114(8.8)$ & $98(11.0)$ & \\
\hline Army/police & $159(7.3)$ & $87(6.7)$ & $72(8.1)$ & \\
\hline \multicolumn{5}{|l|}{ Monthly income (QAR) } \\
\hline$\leq 10,000$ & $945(43.3)$ & $595(46.1)$ & $350(39.3)$ & 0.002 \\
\hline$>10,000$ & $1235(56.7)$ & $695(53.9)$ & $540(60.7)$ & \\
\hline \multicolumn{5}{|l|}{ Place of living } \\
\hline Urban & $2083(95.6)$ & $1230(95.3)$ & $853(95.8)$ & 0.583 \\
\hline Rural & $97(4.4)$ & $60(4.7)$ & $37(4.2)$ & \\
\hline \multicolumn{5}{|l|}{ Housing condition } \\
\hline Villa & $809(37.1)$ & $469(36.4)$ & $340(38.2)$ & 0.594 \\
\hline Apartment & $1299(59.6)$ & $780(60.5)$ & $519(58.3)$ & \\
\hline Traditional house/mud house & $72(3.3)$ & $4 \mid(3.2)$ & $31(3.5)$ & \\
\hline \multicolumn{5}{|l|}{ Smoking habit } \\
\hline Yes & $402(18.4)$ & $264(20.5)$ & I $38(\mid 5.5)$ & 0.003 \\
\hline No & $\mid 778(81.6)$ & $1026(79.5)$ & $752(84.5)$ & \\
\hline \multicolumn{5}{|l|}{ Type of air conditioning } \\
\hline Unit & 1470 (67.4) & $885(68.6)$ & $585(65.7)$ & 0.159 \\
\hline Central & $710(32.6)$ & $405(31.4)$ & 305 (34.3) & \\
\hline \multicolumn{5}{|l|}{ Type of bed mattress } \\
\hline Orthopedic & $829(38.0)$ & 491 (38.1) & $338(38.0)$ & 0.020 \\
\hline Sponge & $1076(49.4)$ & $616(47.8)$ & $460(51.7)$ & \\
\hline Cotton & $275(12.6)$ & $183(14.2)$ & $92(10.3)$ & \\
\hline
\end{tabular}

Notes: Data represent n (\%); two-sided P-values are based on Pearson's Chi-squared test.

Sociodemographic variables play a significant role in the development of LBP. In the study sample, the occurrence of LBP increased with increasing age up to 55 years and then decreased gradually thereafter, which is consistent with a study by Kostova and Koleva. ${ }^{22}$ It was found that
LBP symptoms were consistently more common among the studied women (53.9\%) compared to men (46.1\%). Other studies also reported a similar finding that women were more likely to present with LBP than men. ${ }^{23}$ The higher stress levels among women due to the combination of work-related stress 
Table 2 Mean scores of anxiety, depression, and somatization among subjects with and without LBP

\begin{tabular}{llcc}
\hline Variable & LBP & Without LBP & P-value \\
& $\mathbf{n}=\mathbf{I}=\mathbf{8 9 0}$ & & \\
\hline Mental health severity (mean scores) & & & \\
PHQ-9 depression score (0-24) & $10.1 \pm 3.3$ & $9.0 \pm 3.5$ & $0.00 I$ \\
PHQ-15 somatization score (0-30) & $16.1 \pm 4.3$ & $14.2 \pm 5.6$ & $<0.001$ \\
GAD-7 anxiety score (0-2I) & $8.1 \pm 2.9$ & $6.4 \pm 3.3$ & $<0.001$ \\
\hline
\end{tabular}

Notes: Data represent data \pm standard deviation; two-sided $P$-values are based on Student's $t$-test and Pearson's Chi-squared test; ${ }^{2}$ severe depression indicated by scores $\geq 15$; bsevere somatization indicated by scores $\geq 15$; ' severe anxiety indicated by scores $\geq 11$.

Abbreviations: GAD-7, seven-item Generalized Anxiety Disorder Scale; LBP, low back pain; PHQ-9, Patient Health Questionnaire nine-item depression module; PHQ-15, Patient Health Questionnaire 15-item somatic symptom module.

and stress related to responsibilities for the family might be the reason for the higher incidence of LBP among women. Smoking was significantly more common among studied patients with LBP $(20.5 \%$ versus $15.5 \% ; P=0.003)$, which is in line with a study by Kaila-Kangas et al that associated

Table 3 Distribution of symptoms of somatization, depression, and anxiety in low back pain patients $(n=1290)$

\begin{tabular}{|c|c|}
\hline Symptoms & n (\%) \\
\hline \multicolumn{2}{|l|}{ Somatic symptoms: PHQ-I5 (n = I92) } \\
\hline I. Stomach pain & $60(31.2)$ \\
\hline 2. Pain in your arms, legs, or joints & $74(38.5)$ \\
\hline $\begin{array}{l}\text { 3. Menstrual cramps or other problems with periods } \\
\text { (women only; } n=128 \text { ) }\end{array}$ & $24(18.7)$ \\
\hline 4. Headaches & $79(4 I . I)$ \\
\hline 5. Chest pains & $56(29.2)$ \\
\hline 6. Dizziness & $35(18.2)$ \\
\hline 7. Fainting spells & $33(17.2)$ \\
\hline 8. Feeling heart pound or race & $62(32.3)$ \\
\hline 9. Shortness of breath & $33(17.2)$ \\
\hline 10. Pain or problem during sexual intercourse & $49(25.5)$ \\
\hline II. Constipation, loose bowels, or diarrhea & $66(34.4)$ \\
\hline 12. Nausea, gas, or indigestion & $53(27.6)$ \\
\hline 13. Feeling tired or having low energy & $70(36.5)$ \\
\hline 14. Trouble sleeping & $72(37.5)$ \\
\hline \multicolumn{2}{|l|}{ Depression symptoms: PHQ-9 $(n=177)$} \\
\hline I. Little interest or pleasure in doing things & $82(46.3)$ \\
\hline 2. Feeling down, depressed, or hopeless & $87(49.2)$ \\
\hline 3. Trouble falling asleep, staying asleep, or sleeping too much & $64(36.2)$ \\
\hline 4. Feeling tired or having little energy & $29(16.4)$ \\
\hline 5. Poor appetite or overeating & $54(30.5)$ \\
\hline $\begin{array}{l}\text { 6. Feeling bad about yourself, feeling that you have } \\
\text { let yourself or your family down }\end{array}$ & $47(26.6)$ \\
\hline 7. Trouble concentrating on things & $72(40.7)$ \\
\hline 8. Moving or speaking slowly, being fidgety, or feeling restless & $53(29.9)$ \\
\hline 9. Thinking of suicide or wanting to hurt yourself & $91(51.4)$ \\
\hline \multicolumn{2}{|l|}{ Anxiety symptoms: GAD-7 $(n=122)$} \\
\hline I. Feeling nervous and anxious, or on edge & $5 I(4 I .8)$ \\
\hline 2. Not being able to stop or control worrying & $49(40.2)$ \\
\hline 3. Worrying too much about different things & $49(40.2)$ \\
\hline 4. Trouble relaxing & $25(20.5)$ \\
\hline 5. Feeling so restless that it is hard to sit still & $44(36.1)$ \\
\hline 6. Becoming easily annoyed or irritable & $35(28.7)$ \\
\hline 7. Feeling afraid as if something awful might happen & $49(40.2)$ \\
\hline
\end{tabular}

Abbreviations: GAD-7, seven-item Generalized Anxiety Disorder Scale; PHQ-9, Patient Health Questionnaire nine-item depression module; PHQ-15; Patient Health Questionnaire 15-item somatic symptom module. smoking with LBP. ${ }^{24}$ Studied subjects with an educational level of secondary education (23.6\%) had a higher chance of developing LBP than those with higher educational levels. A similar finding was observed in a recent study by Kwon et al. ${ }^{25}$ In the current study sample, subjects with less than a high school education did not have a high rate of LBP compared to college graduates.

The present study identified that psychological distress was associated with increased risk of LBP. Significant association was observed in studied subjects with LBP with higher mean scores of anxiety $(8.1 \pm 2.9$ versus $6.4 \pm 3.3 ; P<0.001)$, depression $(10.1 \pm 3.3$ versus $9.0 \pm 3.5$; $P=0.001)$, and somatization (16.1 \pm 4.3 versus $14.2 \pm 5.6$; $P<0.001)$. The analysis of other studies indicated that those with LBP scored significantly higher on depression than those without..$^{2-5,22}$ Among the types of psychological distress, somatization was more prevalent in LBP patients, followed by depression and then anxiety. In another study, anxiety presented with the highest prevalence, followed by somatization and then depression. ${ }^{17}$

The study findings describe the psychological issues among LBP patients and show that psychological factors are associated with LBP. Iranian LBP patients have an increased occurrence of coexistent psychological distress, ${ }^{26}$ as has

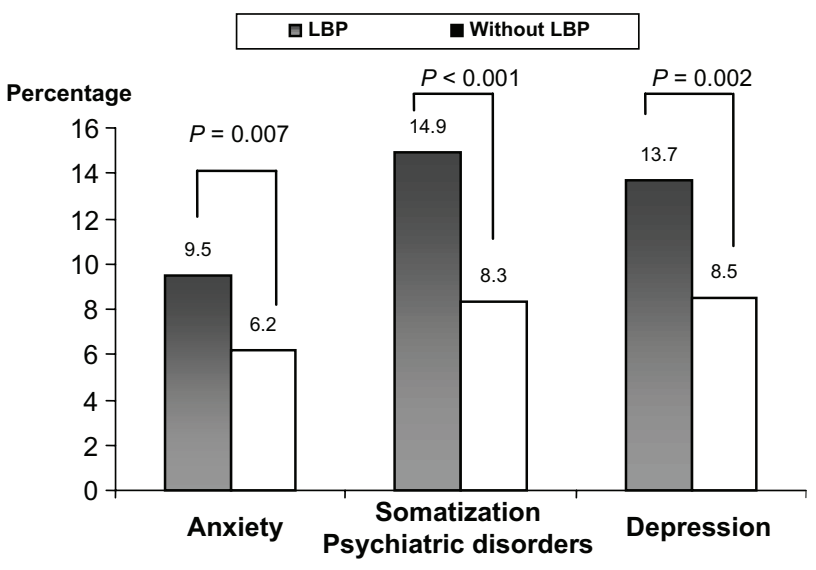

Figure I Distribution of psychiatric disorders in studied subjects with/without low back pain (LBP). 
been shown in the current LBP patient population. In an Australian study, depression was associated with LBP. ${ }^{27}$ The psychological factors associated with LBP show that distress may aggravate the pain. ${ }^{26}$

On the contrary, in a study focused on the impact of anxiety or somatization on the occurrence of LBP, no association was found with anxiety; however, somatization was found to be predictive of disability. ${ }^{28}$ Psychological distress was observed more often in LBP patients in most of the studies. ${ }^{4,5,14,15}$ The most common somatic symptom was "headaches" (41.1\%) and most of the depressed patients were "feeling down, depressed, or hopeless" (49.2\%). Nearly half of the LBP patients with anxiety symptoms (41.8\%) were "feeling nervous and anxious or on edge." LBP poses a significantly greater psychological strain on the patient and is one of the most challenging problems faced by health care consumers as well as health care providers.

LBP patients manifest concurrent psychiatric illness, most commonly depression and somatization. The current study provides epidemiological evidence for the higher frequency and severity of somatization, depression, and anxiety symptoms in patients with LBP compared to patients without LBP. The current findings on LBP and its associated psychosocial factors urge health care practitioners to consider and identify psychological obstacles to recovery. Understanding the importance of the psychosocial pathway in the development of LBP lies not only in the advancement of knowledge in the phenomenon, but also in designing preventive interventions.

\section{Conclusion}

The study findings revealed that LBP is a common problem in the general population. The data indicated that a significant association was observed between psychological distress and the prevalence of LBP. Somatization was more prevalent in LBP, followed by depression. In addition, sociodemographic factors such as age, gender, education, overweight, and smoking were associated factors of LBP.

\section{Acknowledgments}

This work was generously supported and funded by the Qatar Foundation (UREP Grant No 11-074-3-015). The authors would like to thank Hamad Medical Corporation for their support and granting ethical approval (HMC RP\# 12061/12).

\section{Disclosure}

The authors report no conflicts of interest in this work.

\section{References}

1. Wedderkopp N, Leboeuf-Yde C, Anderson LB, Froberg K, Hansen HS. Back pain reporting pattern in a Danish populationbased sample of children and adolescents. Spine (Phila Pa 1976). 2001;26(17):1879-1883.

2. Bener A, El-Rufaie OF, Siyam A, Abuzeid MSO, Toth F, Lovasz G. Epidemiology of low back pain in the United Arab Emirates. Int $J$ Rheum Dis. 2004;7(3):189-195.

3. Walker BF, Miller R, Grant WD. Low back pain in Australian adults: prevalence and associated disability. $J$ Manipulative Physiol Ther. 2004;27(4):238-244.

4. Maniadakis N, Gray A. The economic burden of back pain in the UK. Pain. 2000;84(1):95-103.

5. Bener A, El-Rufaie OF, Kamran S, Georgievski AB, Farooq A, Rysavy M. Disability, depression and somatization in low back pain population. Int J Rheum Dis. 2006;9(3):257-263.

6. Bener A, Al-Kazaz M, Ftouni D, Al-Harthy M, Dafeeah EE. Diagnostic overlap of depressive, anxiety, stress, and somatoform disorders in primary care. Asia Pac Psychiatry. Epub July 23, 2012.

7. Bener A, Alwash R, Gaber T, Lovasz G. Obesity and low back pain. Coll Antropol. 2003;27(1):95-104.

8. Bener A, Ghuloum S, Burgut FT. Gender differences in prevalence of somatoform disorders in patients visiting primary care centers. $J$ Prim Care Community Health. 2010;1(1):37-42.

9. Goldberg DP, Cooper B, Eastwood MR, Kedward HB, Shepherd M. A standardized psychiatric interview for use in community surveys. Br J Prev Soc Med. 1970;24(1):18-23.

10. Kroenke K, Spitzer RL. The PHQ-9: a new depression diagnostic and severity measure. Psychiatr Ann. 2002;32(9):509-515.

11. Spitzer RL, Kroenke K, Williams JB, Lowe B. A brief measure for assessing generalized anxiety disorder: the GAD-7. Arch Intern Med. 2006;166(10):1092-1097.

12. Kroenke K, Spitzer RL, deGruy FV 3rd, Swindle R. A symptom checklist to screen for somatoform disorders in primary care. Psychosomatics. 1998;39(3):263-272.

13. Waddell G. The Back Pain Revolution, 2nd ed. London: Churchhill Livingstone; 2004.

14. Mattila VM, Saarni L, Parkkari J, Koivusilta L, Rimpela A. Predictors of low back pain hospitalization - a prospective follow-up of 57,408 adolescents. Pain. 2008;139:209-217.

15. Dickens C, Jayson M, Creed F. Psychological correlates of pain behavior in patients with chronic low back pain. Psychosomatics. 2002;43(1): $42-48$.

16. Schneider S, Schmitt H, Zolter S, Schittenwolf M. Workplace stress, lifestyle and social factors as correlates of back pain: a representative study of the German working population. Int Arch Occup Environ Health. 2005;78(4):253-269.

17. Manchikanti L, Singh V, Saini B. Epidemiology of low back pain. In: Manchikanti L, Slipman CW, Fellow SB, editors. International Pain Management: Low Back Pain - Diagnosis and Treatment. Paducah, KY: ASIPP Publishing; 2002:3-20.

18. Al-Shammari SA, Khoja TA, Kremli M, Al-Balla SR. Low back pain and obesity in primary health care, Riyadh Saudi Arabia. Saudi Med J. 1994;15:223-226.

19. Delisa JA, editor. Physical Medicine and Rehabilitation, Principles, and Practice, 4th ed. Philadelphia, PA: Lippincott Williams \& Wilkins; 2005:156-167.

20. Palmer KT, Walsh K, Bendall H, Cooper C, Coggon D. Back Pain in Britain: comparison of two prevalence surveys at an interval of 10 years. BMJ. 2000;320(7249):1577-1578.

21. Cassidy JD, Caroll LJ, Cote P. The Saskatchewan health and back pain survey. The prevalence of low back pain and related disability in Saskatchewan adults. Spine (Phila Pa 1976). 1998;23(17):1860-1866.

22. Kostova V, Koleva M. Back disorders (low back pain, cervicobrachial and lumbosacral radicular syndromes) and some related risk factors. J Neurol Sci. 2001;192(1-2):17-25. 
23. Dempsey PG, Burdorf A, Webster BS. The influence of personal variables on work-related low-back disorders and implications for future research. J Occup Environ Med. 1997;39(8):748-759.

24. Kaila-Kangas L, Leino-Arjas P, Riihimaki H, Luukkonen R, Kirjonen J. Smoking and overweight as predictors of hospitalization for back disorders. Spine (Phila Pa 1976). 2003;28(16):1860-1868.

25. Kwon MA, Shim WS, Kim MH, et al. A correlation between low back pain and associated factors: a study involving 772 patients who had undergone general physical examination. J Korean Med Sci. 2006;21(6): 1086-1091.
26. Mirzamani-Bafghi SM, Sadidi A, Sahrai J. Psychological aspects of low back pain. Arch Iran Med. 2003;6(2):91-94.

27. Henschke N, Maher CG, Refshauge KM. Prognosis in patients with recent onset low back pain in Australian primary care: inception cohort study. BMJ. 2008;337:a171.

28. Burton AK, McClune TD, Clarke RD, Main CJ. Long-term follow-up of patients with low back pain attending for manipulative care: outcomes and predictors. Man Ther. 2004;9(1):30-35.

\section{Publish your work in this journal}

The Journal of Pain Research is an international, peer-reviewed, open access, online journal that welcomes laboratory and clinical findings in the fields of pain research and the prevention and managemen of pain. Original research, reviews, symposium reports, hypothesis formation and commentaries are all considered for publication.

\section{Dovepress}

The manuscript management system is completely online and includes a very quick and fair peer-review system, which is all easy to use. Visit http://www.dovepress.com/testimonials.php to read real quotes from published authors. 